\title{
Cochlear implants and bacterial meningitis: A speech recognition study in paired samples
}

\author{
Rubens de Brito', Aline Gomes Bittencourt', Maria Valéria Goffi-Gomez ${ }^{3}$, Ana Tereza Magalhães ${ }^{4}$, Paola Samuel5, Robinson Koji \\ Tsují, Ricardo Ferreira Bento?.
}

1) Otolaryngologist, PhD. Associate Professor, Department of Otolaryngology, University of São Paulo School of Medicine, São Paulo, Brazil.

2) Otolaryngologist, PhD student. Neurotology Fellow, Department of Otolaryngology, University of São Paulo School of Medicine, São Paulo, Brazil.

3) Audiologist, PhD in Human Communication Disorders (Speech Pathology). Department of Otolaryngology, University of São Paulo School of Medicine, São Paulo, Brazil.

4) PhD student. Cochlear Implant Fellow, Department of Otolaryngology, University of São Paulo School of Medicine, São Paulo, Brazil

5) Cochlear Implant Fellow, Department of Otolaryngology, University of São Paulo School of Medicine, São Paulo, Brazil

6) Otolaryngologist, PhD. Associate Doctor, Department of Otolaryngology, University of São Paulo School of Medicine, São Paulo, Brazil

7) Otolaryngologist, PhD. Professor and Chairman, Department of Otolaryngology, University of São Paulo School of Medicine, São Paulo, Brazil.

Institution: Department of Otolaryngology, University of São Paulo School of Medicine

São Paulo / SP - Brazil.

Address for correspondence and reprint requests to Dra. Aline Gomes Bittencourt - Departamento de Otorrinolaringologia, Hospital das Clínicas, Universidade de São Paulo - Av. Dr. Enéas de Carvalho Aguiar, 255, 60 andar/sala 6167 - São Paulo / SP - Brazil - Zip code: 05403-000 - Tel/Fax: (+ 55 11) 3088-0299 - E-mail: alinebittencourt@hotmail.com

Article received on October 17, 2012. Article accepted on October 25, 2012.

\section{SUMMARY}

Introduction: Cochlear implants may guarantee sound perception and the ability to detect speech at a close-to-normal hearing intensity; however, differences have been observed among implantees in terms of performance on discrimination tests and speech recognition.

Objective: To identify whether patients with post-meningitis deafness perform similarly to patients with hearing loss due to other causes.

Method: A retrospective clinical study involving post-lingual patients who had been using Nucleus-22 or Nucleus-24 cochlear implants for at least 1 year. These patients were matched with respect to age ( \pm 2 years), time since the onset of deafness ( \pm 1 year), and the duration of implant use with implant users who had hearing loss due to other causes. Speech perception was assessed using the Portuguese version of the Latin-American Protocol for the Evaluation of Cochlear Implants.

Results: The sample consisted of 52 individuals ( 26 in each of the 2 groups). The post-meningitic group had a median of 18.5 active electrodes. The group with hearing loss due to other causes had a median of 21 , but no significant statistical difference was observed $(\mathrm{p}=0.07)$. The results of closed- and open-set speech recognition tests showed great variability in speech recognition between the studied groups. These differences were more pronounced for the most difficult listening tasks, such as the medial consonant task (in the vowel-consonant-vowel format).

Conclusion: Cochlear implant recipients with hearing loss due to bacterial meningitis, who had been using the device for 1 year performed more poorly on closed- and open-set speech recognition tests than did implant recipients with hearing loss due to other causes.

Keywords: Cochlear implants; Speech perception; Meningitis.

\section{INTRODUCTION}

Cochlear implants are devices that can restore function to the sensorineural system, which controls auditory input. Although cochlear implants guarantee sound perception and the ability to detect speech at a close-tonormal hearing intensity, clinical differences have been observed among implantees in terms of performance on discrimination tests and speech recognition (1).

Bacterial meningitis is a common cause of hearing loss in Brazil. In some cases of post-meningitic deafness (PMD), the lesion extends to spiral ganglion cells, neural fibers and the brainstem, which may impair sound processing and hinder speech discrimination (2,3). Another important issue related to PMD is labyrinthitis ossificans (LO). This situation can occur in up to $80 \%$ of cases and prevent correct insertion of the implant electrode array (4).

There are 2 approaches for the appropriated management of PMD (5). The conservative approach recommends that implant insertion be delayed after deafness onset to allow for careful observation of any early signs of LO. This allows the physician to monitor the patient for any recovery of hearing. The interventionist approach recommends early implantation to avoid surgical complications in a cochlea with any degree of ossification (6). 
PMD must be managed with consideration to spiral ganglion cells, neural fiber lesions and the LO. Decisions as to the timing of surgery and whether to perform a bilateral implantation must account for the patient's hearing prognosis. Although the LO is the main concern regarding hearing outcomes after cochlear implantation, there is still a sense that deafness due to meningitis in patients with a patent cochlea differs from that in patients with hearing loss due to other causes.

The objective of this study was to identify whether patients with post-meningitis deafness perform similarly to patients with other types of hearing loss.

\section{METHOD}

This was a retrospective clinical study (database collection)

Selection criteria involved:

- Users of Nucleus-22 or Nucleus-24 cochlear implants for at least 1 year.

- Post-lingual deafness.

- Imaging studies demonstrating appropriate insertion of the electrode arrays.

- An average sound-field threshold (500-4,000 Hz) $>40$ dB HL.

Subjects were divided into 2 groups: Group 1 included patients with post-meningitic deafness and Group 2 included those with hearing loss due to other causes. Patients in both groups were matched with respect to age ( \pm 2 years), time since the onset of deafness ( \pm 1 year) and the duration of implant use. All of them were implanted with a Nucleus device with straight-array electrodes. Speech perception was assessed based on the Portuguese version of the Latin-American Protocol for the Evaluation of Cochlear Implants (7). All tests were administered in the auditoryonly condition. The open-set speech recognition tests involved sentences; trisyllabic, dissyllabic, and monosyllabic words; and medial consonants in the vowel-consonantvowel (VCV) format. The test used in closed format was vowel perception (vowels presented in consonant-vowelconsonant [CVC] format). The performance of individuals was measured by the percentage of correct responses per test. All tests were applied 12 months after the device had been activated.

Programming in all Nucleus-24 patients was performed using the ACE strategy in monopolar stimulation, while that in all Nucleus-22 patients was performed using the SPEAK strategy in bipolar stimulation. A number of active electrodes were collected for each patient. The reasons for switching off the electrodes were facial nerve stimulation, pain sensation, or lack of auditory sensation with the maximum current level ( 255 current units) even after an increase in pulse width ( $\leq 100 \mathrm{~ms})$.

The statistical analysis was performed using the Wilcoxon test for paired samples.

\section{RESULTS}

Of the eligible implantees with hearing loss due to bacterial meningitis, 25\% were excluded due to a mean sound field threshold $>40 \mathrm{~dB} \mathrm{HL} ; 3 \%$ of those with hearing loss due to other causes were excluded for the same reason. The final sample consisted of 52 individuals ( 26 in each of the 2 groups). The demographic data related to the study sample are presented in Table 1. Group 1 had a median of 18.5 active electrodes and group 2 had a median of 21 active electrodes, but no significant statistical difference was observed $(\mathrm{p}=0.07)$.

Figure 1 shows the results of closed- and open-set speech recognition tests for each group.

\section{DISCUSSION}

The aims of this study were to contribute to the clinical decision process by reporting on the outcomes of cochlear implantation in patients with PMD and elaborate the hypotheses regarding the differential outcomes of cochlear implantation in patients with deafness due to other causes.

Table I. Demographic data related to the study sample.

\begin{tabular}{lcc}
\hline & $\begin{array}{c}\text { Groupl } \\
(\mathrm{N}=26)\end{array}$ & $\begin{array}{c}\text { Group II } \\
(\mathrm{N}=26)\end{array}$ \\
\hline Male $(\mathrm{N})$ & 14 & 12 \\
Female $(\mathrm{N})$ & 12 & 14 \\
Age (years) at the time of surgery, mean & 30.5 & 32 \\
Time (years) since the onset of deafness, & \\
mean & 12.6 & 10.7 \\
Nucleus-22 & 7 & 5 \\
Nucleus-24 & 19 & 21 \\
Median numberofactive electrodes & $18.5( \pm 4)$ & $21( \pm 1)$ \\
Sound field threshold $(\mathrm{dBHL}) *$, mean & $34.12 \pm 8.628 .7 \pm 9.0$
\end{tabular}

Group I: Cochlear implantees with post-meningitic deafness; Group II: Cochlear implantees with hearing loss due to other causes.

*From 500-4000 Hz (BIAP, 1996). 


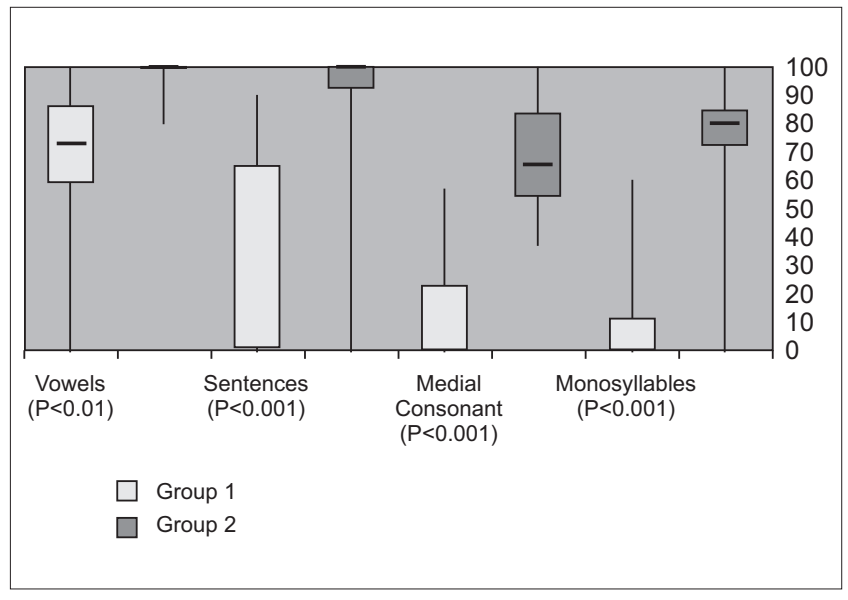

Figure 1. Boxplot of the results (\% of correct responses) of each speech recognition test of both studied groups, Group I (cochlear implantees with postmeningitic hearing loss) in light shadow, and Group II (cochlear implantees with hearing loss due to other etiologies) in dark shadow. P-values were obtained using the Wilcoxon test for paired samples.

Great variability in speech recognition was observed between the groups. These differences were more pronounced in the most difficult listening tasks, such as the medial consonant task (in the vowel-consonant-vowel format). In Group 1, speech perception scores ranged from $65-100 \%$ for the easiest task (vowel identification, a 4-choice task in Portuguese) and from 0-32\% for the most difficult task (medial consonant identification [VCV], an open set task). In Group 2, speech perception scores were consistently $100 \%$ for the easiest task (vowel identification) and ranged from 55-95\% for the most difficult task (VCV). The literature also mentions poorer performance in the adult population with PMD (8).

As we matched patients with respect to age $( \pm 2$ years), deafness duration ( \pm 1 year), and length of implant use ( \pm 1 year), the marked differences in speech recognition may reflect the different intracochlear and central auditory system pathologies in PMD patients, electrode insertion depth, the number of active electrodes and/or the ability to perceive differences in pitch (9-12).

Although only patients with access to speech sounds (i.e., sound field thresholds better than $40 \mathrm{~dB} \mathrm{HL}$ ) were included in this study, we found that $25 \%$ of the PMD patients implanted at our center were excluded because of thresholds higher than this cutoff value. This fact shows that PMD patients might not have the capacity for speech detection even with cochlear implants. These patients are among those with total auditory obliteration and should be considered as candidates for an auditory brainstem implant (ABI) $(13,14)$.
In our study, Group 1 had a median of 18.5 active electrodes; Group 2 had a median of 21 active electrodes, with no statistical difference between the groups. Nevertheless, frequency allocation inaccuracies might influence speech recognition. Sridhar et al. studied the frequency-position function for the human spiral ganglion (SG) and found that the SG ranged in length from 12.54 $14.62 \mathrm{~mm}$. This is $40-43 \%$ of the length of the organ of Corti, which generally ranges from $30.5-36.87 \mathrm{~mm}$ (15). Unlike critical bandwidths for the organ of Corti, which remain constant along the cochlea, estimated band distances in the SG diminish systematically from base to apex. This point is extremely important when considering electrodes that are switched off. Hence, the ability to perceive pitch does not rely only on the number of active channels but also on their position along the array, especially in PMD patients. In a recent study, we showed that the spread of excitation function among PMD patients is considerably poorer than in patients with hearing loss due to other causes (16).

All of the speech tests highlighted statistically significant differences between the groups. The findings of a longitudinal study that assessed cochlear implant use in children with hearing loss due to bacterial meningitis or other causes were worse than those of adults with hearing loss due to bacterial meningitis (3). Other studies involving adults with post-lingual hearing loss due to meningitis or other causes have also shown that patients with hearing loss due to bacterial meningitis performed more poorly on speech perception tests $(2,17)$. Wellman et al. reported no statistically significant differences in terms of speech recognition between a group of children with hearing loss due to bacterial meningitis and a group of children with hearing loss due to various other causes; all received cochlear implants during the pre-lingual period (18). It must be noted that other factors, such as the rehabilitation method employed and stimulation received, influence the results in children with pre-lingual hearing loss $(19,20)$.

However, there were some good performers (>70\% of sentence recognition, $>50 \%$ monosyllable recognition) within the group of PMD adults. Francis et al. (2004) studied 30 PMD children and found that the presence of post-meningitic hydrocephalus posed a significant challenge to speech perception outcomes and led to a predilection for behavioral problems (21). These authors also showed that cochlear scarring and incomplete electrode insertion had no impact on speech perception. It is probable that incomplete insertion, as opposed to electrodes that are switched off, takes advantage of the more populated cochlearbase.

It has been hypothesized that adult patients with hearing loss due to bacterial meningitis present fewer spiral 
ganglion cells due to the particular features meningitisrelated lesions in the hearing system. The time since onset of deafness is essential for this degeneration (2).

There is still no evidence that the meningitis causative agent is related to a better or worse prognosis. Additionally, with the analysis of more than 1600 cases of meningitis, it was found that there is no causative agent of meningitis that is more likely to cause LO, although there is a higher risk that Streptococcuspneumoniae meningitis may cause profound hearing loss (22). Less populated spiral ganglions may be observed in such cases (12).

The degree of neural survival is an important factor for the ability to process speech stimuli. Therefore, more accurate determination of the neural structures that can be stimulated with electrical impulses would be quite useful, because it is assumed that the survival of ganglion cells and other elements of central auditory pathways might constitute one of the causes of the variable speech recognition performance found among implantees $(21,23)$.

We observed that other variables, such as differences in implant technology and cochlear patency, might influence outcomes. These variables will be considered in our future studies.

\section{CONCLUSION}

Cochlear implant recipients with hearing loss due to bacterial meningitis, who have been using the device for 1 year performed more poorly on closed- and open-set speech recognition tests than did implant recipients with hearing loss due to other causes, who used the device for the same period of time.

\section{REFERENCES}

1. Bento RF, Brito neto RV, Castilho AM, Gomez MVSG, Giorgi SB, Guedes MC. Resultados auditivos com o implante coclear multi-canal em pacientes submetidos a cirurgia no Hospital das Clínicas da Faculdade de Medicina da Universidade de São Paulo. Rev Bras Otorrinolaringol. 2004;70(5):632-7.

2. Blamey P, Arndt P, Bergeron F, Bredberg G, Brimacombe J, Facer G, et al. Factors affecting auditory performance of postlinguistically deaf adults using coclhear implants. Audiol Neurootol. 1996;1(5):293-306.

3. El-Kashlan HK, Ashbaugh C, Zwolen T, Telian AS. Cochlear implantation in prelingually deaf children in ossified cochleae. Otol Neurotol. 2003;24(4):596-600.
4. Steenerson RL, Gary LB, Wynens MS. Scala vestibuli cochlear implantation for labyrinthine ossification. Am JOtol. 1990;11:360-3.

5. Philippon D, Bergeron F, Ferron P, Bussieres R. Cochlear implantation in postmeningitic deafness. Otol Neurotol. 2009;31:83-7.

6. Nichani J, Green K, Hans P, Bruce I, Henderson L, Ramsden R.Cochlear implantation after bacterial meningitis in children: outcomes in ossified and nonossified cochleas. Otol Neurotol. 2011;32(5):784-9.

7. Gomez MVSG, Guedes MC, Sant'Anna SBG, Peralta CGO, Tsuji RK, Castilho AM, et al. Critérios de Seleção e Avaliação Médica e Audiológica dos Candidatos ao Implante Coclear: Protocolo HC-FMUSP. Arq Int Otorrinolaringol. 2004;8(4):303-23.

8. Mosnier I, Ambert-Dahan E, Smadja M, Ferrary E, Bouccara D, Bozorg-Grayeli A, Sterkers O. Performances and complications of cochlear implant in 134 adult patients implanted since 1990. Ann Otolaryngol Chir Cervicofac. 2006;123(2):71-8.

9. Macandie C, Singh R. Meningitis and cochlear implantation in Scotland. Cochlear Implants Int. 2000;1(2):108-13.

10. Eshraghi AA, Telischi FF, Hodges AV, Odabasi O, Balkany TJ. Changes in programming over time in postmeningitis cochlear implant users. Otolaryngol Head Neck Surg. 2004;131(6):885-9.

11. Francis HW, Buchman CA, Visaya JM, Wang NY, Zwolan TA, Fink NE, Niparko JK. Surgical factors in pediatric cochlear implantation and their early effects on electrode activation and functional outcomes. Otol Neurotol. 2008;29(4):502-8.

12. Douglas SA, Sanli H, Gibson WP. Meningitis resulting in hearing loss and labyrinthitis ossificans - does the causative organism matter? Cochlear Implants Int. 2008;9(2):90-6.

13. Sanna M, Khrais T, Guida M, Falcioni M. Auditory brainstem implant in a child with severely ossified cochlea. Laryngoscope. 2006;116(9):1700-3.

14. Grayeli AB, Kalamarides M, Bouccara D. Auditory Brainstem Implant in Neurofibromatosis Type 2 and NonNeurofibromatosis Type 2 Patients. Otol Neurotol. 2008;29:1140-6.

15. Sridhar D, Stakhovskaya O, Leake PA. A frequency- 
position function for the human cochlear spiral ganglion. Audiol Neurotol. 2006;11(suppl 1):16-20.

16. Goffi-Gomez MV, Abdala CF, Peralta CG, Tsuji RK, Brito R, Bento RF. Neural response telemetry in patients with the double-array cochlear implant. Eur Arch Otorhinolaryngol. 2010;267(4):515-22.

17. Green JD, Marion MS, Hinojosa R. Labyrinthitis ossificans: histopathologic consideration for cochlear implantation. Otolaryngol Head Neck Surg. 1991;100:712-6.

18. Wellman MB, Sommer DD, McKenna J. Sensorineural hearing loss in postmeningitic children. Otol Neurotol. 2003;24(6):907-12.

19. Bevilacqua MC, Moret al.M, Costa Filho OA, Nascimento LT, Banhara MR, Cochlear implant in deaf children due to meningites. Braz J Otorhinolaryngol. 2003;69(6):760-4.
20. Fitzpatrick E, McCrae R, Schramm D. A retrospective study of cochlear implant outcomes in children with residual hearing. BMC Ear Nose Throat Disord. 2006;6:7.

21. Francis HW, Pulsifer MB, Chinnici J, Nutt R, Venick HS, Yeagle JD, Niparko JK. Effects of central nervous system residua on cochlear implant results in children deafened by meningitis. Arch Otolaryngol Head Neck Surg. 2004;130(5):604-11.

22. Roukema BY, Van Loon MC, Smits C, Smit CF, Goverts ST, Merkus P, Hensen EF. Cochlear implantation after bacterial meningitis in infants younger than 9 months. Int J Otolaryngol. 2011;2011:845-879.

23. Guedes MC, Weber R, Gomez MV, Brito R, Peralta CG, Bento RF. Influence of evoked compound action potential on speech perception in cochlear implant users. Braz J Otorhinolaryngol. 2007;73(4):439-445. 